\title{
Touching history
}

\section{Activating historical materials and enhancing inclusivity in the library}

I

$n$ recent decades there have been great efforts by

librarians to integrate digital infrastructure and resources within academic libraries. Over the past two decades, important steps have been taken in Hong Kong towards historical and cultural preservation. However, it is crucial that users engage with these resources. When compared with contemporary tools and platforms of research favored by students nowadays, such as Google or Wikipedia, accessing and analyzing primary resources, whether digital or physical, is not a particularly easy or convenient task for students who have not been trained to do so.

In 2015, the Run Run Shaw Library at the City University of Hong Kong, initiated the Lighthouse Heritage Research Connections (LHRC) Project. ${ }^{1}$ The LHRC Project is a service-learning initiative that has been working to encourage students, as well as the public, to meaningfully engage with Hong Kong's archives. Hong Kong's history is, to a great extent, a maritime history, and Hong Kong's heritage is inextricably tied to the oceans that surround it. Lighthouses reveal much about this history, from the micro narratives to the global context. The LHRC Project strives to stimulate students' engagement with Hong Kong's history, and show them why, and in which ways, this history is personally relevant and important to them. Just glimpsing the complex and interconnected flux of events that characterize the history of Hong Kong, and the stories of the people and places within this, can, somewhat paradoxically, give students a stronger sense of cultural belonging and identity, while at the same time blur and complicate the idea of where Hong Kong-its people, culture and history-actually starts and ends.
The LHRC Project brings students from different backgrounds together to learn from the unique perspectives and strengths of one another. Students from numerous cultures and fields of study have brought their various talents, skills, and interests to the project to participate in a variety of different ways. Some examples of how students have contributed within the LHRC Project include conducting focused research on different aspects of lighthouse heritage, helping with the transcription and translation of archival documents, creating digital renderings and artwork, taking part in study trips, documenting photographs, developing film documentaries, and acting as curators or general organizers of events and exhibitions. As these examples indicate, the project emphasizes interdisciplinary activities and research, such as the digital reconstruction of a historic, long demolished lighthouse, ${ }^{2}$ and an examination of the economics, management, and accounting practices of a Chinese lighthouse. ${ }^{3}$ In the LHRC Project, the library serves its role as an activity hub for interdisciplinary knowledge transfer.

In 2020, the LHRC Project team again welcomed a new member, named Samantha, who brought with her a totally new perspective to lighthouse heritage research. Samantha is one of an estimated 7,800 Hong Kongers who is completely blind. ${ }^{4}$ Needless to say, the absence of

Steve Ching is special advisor to Run Run Shaw Library, email: hsching@cityu.edu.hk, and Brad New is research associate of Lighthouse Heritage Research Connections, email: brad_new@live.com.au, at the City University of Hong Kong

(C) 2021 Steve Ching and Brad New 
sight has implications for the way in which blind and visually impaired students interact with information. Yet, as is true of sighted students, digital new-media technology can also offer new options for enhancing accessibility and stimulating interest in the Humanities for the blind and visually impaired.

\section{Samantha's role as curator}

Samantha became involved in the LHRC Project in February 2020, after a chance encounter with a librarian who had met her previously. This librarian, who had connections with the Hong Kong Blind Society, invited Samantha to the library to check out some of the recent work that had been done as part of the LHRC Project. During the tour, it became apparent that Samantha had a perspective that could help the project grow, in consideration of others who are visually impaired. As a result, it was discussed whether Samantha had any interest in joining the project as an active team member, to which she enthusiastically accepted.

Most of the work done by students in the LHRC Project is consolidated and presented through an exhibition or documentary film. The media of film can be suitable for a blind and visually impaired audience, so long as enough consideration is given to the audio aspects of the film. As for exhibitions, however, it is not always so obvious or clear how to create a more accessible and inclusive experience for blind and visually impaired visitors. In truth, many exhibitions, whether in art galleries, museums, or libraries, are overwhelmingly ocular-centric, and do not offer much for blind or visually impaired visitors. Even when an individual display is not exclusively visual, the description of the display, which can offer so much insight, quite often is. Braille descriptions are still uncommon, and although audio descriptions are becoming more common, they are far from ubiquitous.

During a three-month period from February to May, Samantha was an active LHRC Project team member, who worked alongside sighted students to revise and develop displays for an upcoming exhibition to increase accessibility for other blind and visually impaired visitors. At the same time, Samantha developed such a thor- ough and confident knowledge of the exhibition themes, that she was able to provide guided tours for sighted and blind visitors alike.

\section{The exhibition}

The exhibition Samantha helped prepare took place across two locations, with slight differences between each manifestation. The first, which took place at the Hong Kong Maritime Museum on the May 16-17, 2020, was titled "Chasing Lighthouse Heritage." This exhibition coincided with International Museum Day 2020. The theme for this year's annual event was "Museums for Equality: Diversity and Inclusion," a theme that was chosen with the aim of "create[ing] meaningful experiences for peoples of all origins and backgrounds." 5 This exhibition was an overwhelming success, attracting more than 2,000 visitors.

The second manifestation of the exhibition was titled "Chasing Hong Kong and Penghu Lighthouse Heritage: A Mini Exhibition with Audio Description Guided Tour," and took place at the City University of Hong Kong from the July 22-29. Due to COVID-19-related restrictions on who could enter the university campus during this period, this second exhibition was primarily attended by visitors from the university, students, and staff, whereas the first was available to the public.

The exhibition showcased primary resources from the library's digital archives, including an historical Hong Kong government gazette and Hong Kong's first Chinese newspaper. Founded in 1853, the newspaper, titled Chinese Serial 《遐邇貫珍》, introduced western history, geography, and sciences to Chinese readers, and also reported the latest news in China and the West. The first Chinese language article about western lighthouses was recorded in this newspaper in 1856. Hong Kong's first lighthouse and one of East Asia's earliest, the Cape D'Aguilar Lighthouse, was designed 18 years later, in 1874 , with the construction completed the following year. This newspaper marked the early origins of an important phase in East Asia's maritime history, particularly the crosscultural influence of ideas, and therefore was featured in the exhibition and used to demonstrate to the LHRC 


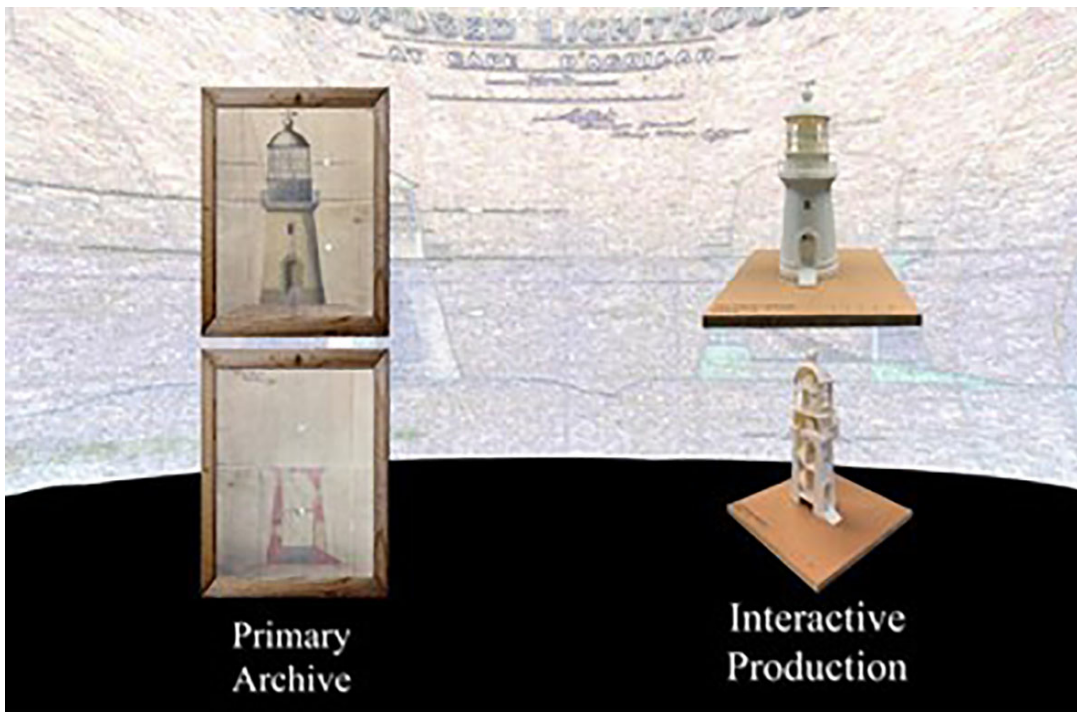

Figure 1. 3-D models of the Cape D'Aguilar Lighthouse (Hong Kong) produced from archival documents (sourced from The National Archive, UK). due to war and technological developments. Although these were not originally created out of consideration for a blind and visually impaired audience, they do have the benefit of being objects which can be un-

Project team and public audiences the central derstood through touch, and are therefore position of lighthouses in Hong Kong's global appropriate for such visitors. and interconnected roots.

To prepare for the exhibition, Saman-

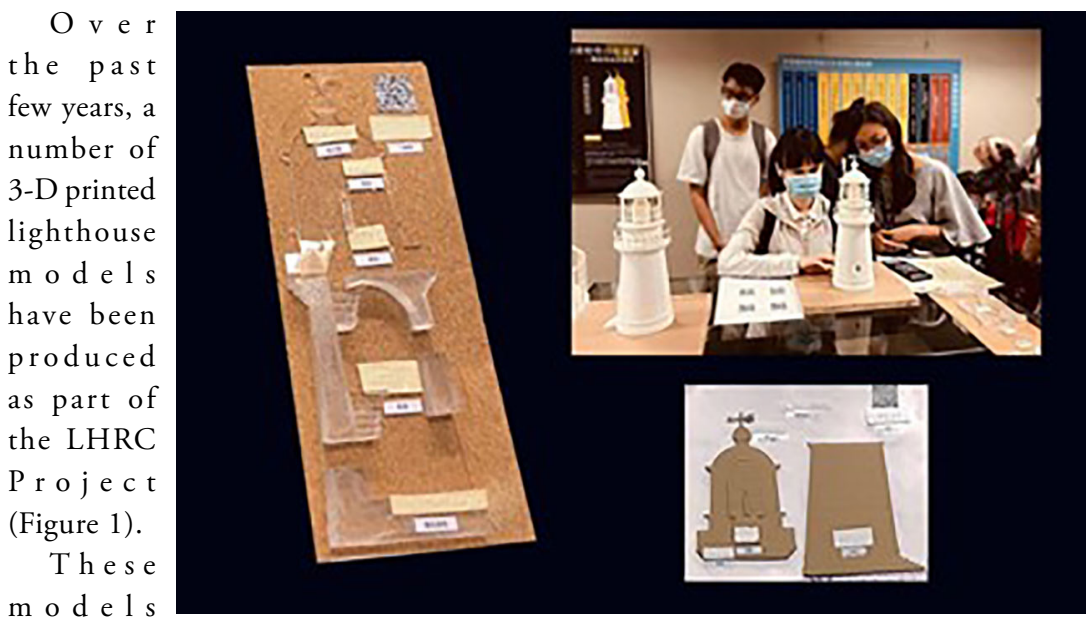

were recon- Figure 2. Tactile displays of lighthouse structural components designed structions by Samantha (left, bottom). A visually impaired visitor experiences 3-D produced model (top right.)

from blue-

prints, photographs, and information contained within archival documents, collected and compiled by another LHRC Project participant named Adam, who has an architecture and design study background. It is notable that these reconstructions are of the lighthouses as they appeared originally, but have since been altered tha worked c lo s e ly alongside Adam and revised these displays . Through this partnership, Samantha became familiar with the physical makeup and char-

acteristics of specific lighthouses in a way that would not have been possible or practical through visiting life- sized lighthouses. Through her own learning experience, Samantha went on to facilitate the creation of acrylic tactile drawings with braille to help others who are blind or visually impaired better understand certain aspects of the lighthouses (Figure 2). 
Naturally, the exhibition had a number of displays that were of texts retrieved from the digital archives. In these cases, auditory recordings, available in both English and Cantonese, were developed by students from the Department of Linguistics and Translation. These students also assisted with the translation of some historical texts used in the exhibition, including the aforementioned early Hong Kong newspaper article on western

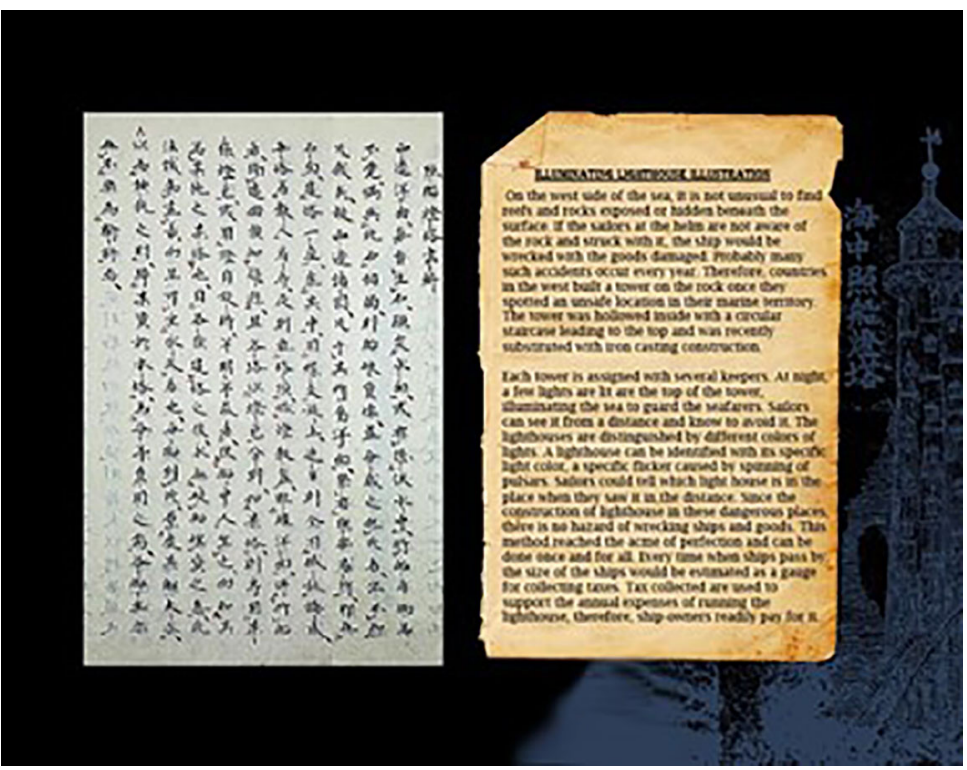

Figure 3. English translation (right) of Hong Kong newspaper article (遐邇貫 珍) describing the Cape D'Aguilar Lighthouse (archived in Saga Prefecture Library, Japan). lighthouses (Figure 3).

As mentioned, braille was integrated into the displays to aid with descriptions. In the case of a calligraphy artwork display, a braille version of the artwork's content, as well as a raised tactile version of the artwork's form were both included. The second exhibition included two additional three-dimensional models that were made with more simplified characteristics, as well as more audio descriptions.

\section{Documentaries and seminar}

In addition to the exhibition, two documentary films were created to showcase the research and activities of the LHRC Project. The first documentary, titled Cape D'Aguilar Lighthouse, ${ }^{6}$ told the story of Hong Kong's first lighthouse through the voices of locals, experts, and archival materials. The other documentary, Glow from the Other Side, ${ }^{7}$ was first proposed by some LHRC student participants who were inspired after witnessing the partnership between Samantha and Adam, whereby normal barriers were transcended through a close working relationship and shared goals. The students had witnessed Samantha go from someone with only a very basic conceptual un-

derstanding of lighthouses, to a person with a thorough understanding of even specific lighthouses and their components and histories. This documentary traced Samantha's first experience of visiting and touching a lighthouse, the Cape D'Aguilar lighthouse, which, given the remoteness and difficulty of accessing the site, is no small matter.

Following the premier screenings of both documentaries on May 16 at the Hong Kong Maritime Museum, there was a seminar that focused largely on the two documentaries, but also included discussion about inclusive practices in academic libraries, exhibitions and pedagogy, and archival preservation. In attendance was the museum director, librarians from CityU and the Chinese University of Hong Kong, teachers, community leaders, lighthouse enthusiasts, and of course LHRC Project team members, including Adam and Samantha.

\section{Final thoughts and future plans}

It is our firm belief that through the LHRC Project, the library can act as a bridge between different fields of knowledge and aggregate students from various academic backgrounds

(continues on page 69) 
all the nuances of functioning in a virtual meeting environment. We also learned the hard way the limitations of working through a VPN to access our remote desktops. The experience made us all more flexible and confident with new technology.

We also learned how to pace ourselves. In a normal office environment, you step away from your computer for meetings, workshops, and seminars. At home, the fully virtual experience was initially exhausting until we learned to take a break from our projects and take a webinar about something unrelated to archives. We also spent time reading books by local historians and articles about archival best practices, so we didn't spend all of our time in front of a computer screen.

As we have reacclimated to working in the library, we have found that the projects we completed while we were working remotely made our workflow more efficient and productive. Although we will be happy to see the eventual end of the COVID-19 pandemic and the pain and disruption caused by it, we were able to create a stronger department from our experience.

\section{Notes}

1. See https://www.unf.edu/library /specialcollections/.

2. Our standard Conditions Governing Use: "Materials in the collection may be subject to copyright and are to be used for private study, scholarship, or research in accordance with the copyright law of the United States (Title 17, United States Code). Use of reproductions of copyrighted works in excess of " fair use," may result in the user's liability for copyright infringement and be subject to the civil and criminal penalties of federal law. Visit the United States Copyright Office's website at http:// www.copyright.gov/ for further information."

3. Our standard Preferred Citation: "XYZ Collection, Thomas G. Carpenter Library, University of North Florida, Jacksonville, Florida."

4. See https://archives.unf.edu/repositories/ resources for our most recent finding aids. The new and "cleaned-up" finding aids have identifiers consistent with current best practices: 2XXX(year collection acquired).00X(number of collection acquired that year). For example, the identifier 2020.001 refers to the first accession in 2020. $\pi$

("Touching history," continued from page 65)

to contribute their unique strengths. Doing so gives students the chance to acquire knowledge beyond their own fields of expertise and, as a result, provides students with invaluable learning experiences. Henceforth, our project team aims to further our work which emphasizes the process of knowledge transfer. We will continue to transform archives into exhibits, and words into braille and audio descriptions for people with visual impairments. When circumstances regarding the current pandemic crisis allow, we hope to host another exhibition at the Hong Kong Maritime Museum, expanding upon earlier work to include more auditory and tactile displays, as well as the publication of an exhibition display guide written in text and braille.

Additionally, 12 students from the Department of Linguistics and Translation will work together to produce an audiobook on Hong Kong's lighthouse history. Finally, we will continue our partnership with the Special Education Needs Office, and hope to attract more blind and visually impaired students to take part in the LHRC Project for many years to come.

Although some students may have different needs with regards to accessing, understanding, and using information, all students have the same rights to relevant and useful information in their chosen format. As with all students, the blind and visually impaired have their own strengths and insights that can help create a balanced learning experience that benefits everyone. During the working process, the LHRC team became more familiarized with the unique needs and strengths of their visually impaired classmates. They also gained a new appreciation for "fairness" when planning and initiating the exhibition, a value which is

(continues on page 79) 
tion: JMLA vol. 102,4 (2014): 227-9, https://doi. org/10.3163/1536-5050.102.4.001.

2. ACRL, "Framework for Information Literacy for Higher Education," (2016), www.ala. org/acrl/standards/ilframework.

3. Peter M. Senge, The fifth discipline fieldbook: Strategies and tools for building a learning organization (New York: Crown Business, 2014).

4. Jonathan Levene, "Solving the problem with problem-solving meetings," https://www. extension.harvard.edu/professional-development /blog/solving-problem-problem-solving-meetings (accessed April 14, 2020).

5. Sarah Blakeslee, "The CRAAP Test," LOEX Quarterly 31, no. 3 (2004), https://commons. emich.edu/cgi/viewcontent.cgi?article=1009\&context =loexquarterly.

6. John McManus, “Don't Be Fooled: Use the SMELL Test To Separate Fact from Fiction Online," (2013), http://mediashift.org/2013/02 /dont-be-fooled-use-the-smell-test-to-separate -fact-from-fiction-online038/.

7. Sam Wineburg and Sarah McGrew, "Lateral Reading: Reading Less and Learning More When
Evaluating Digital Information," Stanford History Education Group-Working Paper (September 2017), https://papers.ssrn.com/sol3/papers. cfm?abstract_id=3048994.

8. Jennifer A. Fielding. "Rethinking CRAAP Test: Getting students thinking like fact-checkers in evaluating web sources," (2019), https://crln.acrl. org/index.php/crlnews/article/view/24195/32005.

9. Helena Hollis, "Information literacy and critical thinking: different concepts, shared conceptions," (2019), http://www.informationr.net /ir/24-4/colis/colis1921.html\#author.

10. The National Council for Excellence in Critical Thinking, "Defining Critical Thinking," (1987), http://www.criticalthinking.org/pages/ defining-critical-thinking/766.

11. ACRL, "Framework for Information Literacy for Higher Education," (2016), www.ala. org/acrl/standards/ilframework.

12. Jennifer A. Livingston, "Metacognition: An Overview," online paper, State University of New York at Buffalo, Graduate School of Education (1997).

13. https://sandbox.acrl.org/librarycollection/4-step-source-assessment-strategy. 22

("Touching history," continued from page 69)

certainly applicable to many areas of life, study, and work, and absolutely integral to achieving inclusivity within societies.

\section{Notes}

1. Steve H. Ching, "Turning a Service Learning Experience into a Model of Student Engagement: The Lighthouse Heritage Research Connections (LHRC) Project in Hong Kong," Journal of Academic Librarianship 44, no. 2 (2018): 196-206, https://doi.org/10.1016/j. acalib.2018.02.007.

2. Anthony K. H. Leung, Stephen Davies, and Steve H. Ching, "When new technology joins old documents and east meets west: virtually reconstructing the Fisher Island pagoda lighthouse (China)," Virtual Archaeology Review 18, no.9 (2018).

3. Richard W. L. Wong, Anthony K. H.
Leung, Brad New, and Steve Ching, "Digital Forensic Investigation of the Xiyu Pagoda Lighthouse: A Library-Led Interdisciplinary Research Project," International Journal of Art, Culture and Design Technologies 9, no. 2 (2020).

4. Hong Kong Blind Union, "About VI," https://www.hkbu.org.hk/en/knowledge/statistics /index (accessed August 13, 2020).

5. See https://www.hkmaritimemuseum.org /eng/learn/hkimd2020-lighthouse-memories -diversity-inclusion/chasing-lighthouse-heritage -hong-kong-lighthouse-heritage-research -conections-city-university-of-hong-kong /135/254/.

6. See https://www.cityu.edu.hk/cityvod /video/play/LIB/lighthouse_memories_13.aspx.

7. See https://www.cityu.edu.hk/cityvod /video/play/LIB/lighthouse_memories_14.aspx. z 